\title{
Harmonic Reduction in Single Boost Converter Fed DC Motor with EMI Input Filter
}

\author{
A.Sivakumar ${ }^{1}$, T. Muthamizhan ${ }^{2}$ \\ ${ }^{1}$ Department of EEE, Anna University, Chennai, India, \\ ${ }^{2}$ Sai Ram Institute of Technology, Chennai, India
}

\begin{tabular}{l} 
Article Info \\
\hline Article history: \\
Received Dec 21, 2017 \\
Revised Jan 22, 2018 \\
Accepted Feb 7, 2018 \\
\hline
\end{tabular}

Keyword:

DC motor

EMI input filter

Single boost converter

THD

\begin{abstract}
DC motor drive system supplied by AC/DC rectifier topology considered as a nonlinear load. It produces harmonic distortions and EMI noise effects in the power systems. In this paper deals with the reduction of supply current harmonics and EMI noise generated by the power electronics converter in the DC motor drive using FFT analysis. The single boost converter along with EMI input filter is proposed in this system to investigate the harmonic reduction in the DC motor drive. The single boost converter fed DC motor drive is modeled and simulated using MATLAB/Simulink software. The simulation results show better agreement with the proposed system.
\end{abstract}

Copyright $@ 2018$ Institute of Advanced Engineering and Science. All rights reserved.

\section{Corresponding Author:}

A.Sivakumar,

Departement of Electrical and Electrical Engineering,

Panimalar Engineering College,

Nazarathpet, Poonamallee, Chennai, India.

Email: arunsiva75@gmail.com

\section{INTRODUCTION}

Recent trends, increasing use of power electronic converter based loads like UPS, SMPS, rectifiers, inverters, motor drive systems, etc., in many applications due to deliver the power with maximum efficiency, minimum cost and weight in an integrated circuit. These loads are termed as a nonlinear load and cause an electrical noise pollution in the power system by injecting harmonics, EMI noises voltage distortions and associated power quality issues. EMI noise produced by power electronic converters is a serious problem in the connected and neighboring network due to the conducted EMI emissions. EMI filters are essentially required to reduce the electrical noise at considerable range. The EMC design of power converters is based on the EMI noise analysis and its propagation paths. Various research articles have been reported on the EMI analysis of power converters and SMPS using different filter topologies and techniques. The passive and active EMI filters are adopted for reducing the EMI noise levels and enhance the power factor.

The modeling and simulation approach gives a suitable design for building the final hardware prototypes because it is a difficult and time-consuming process. The EMI filters are introduced to minimize the undesirable electrical noises or disturbances in power lines; power supplies (SMPS) and power converters. The compensation of these harmonics and EMI noise effects has recently been attracting more interest to the power system engineers with suitable filtering techniques. The EMI filters are two types such as passive and active filters. The series type active filter is installed series with the nonlinear loads or harmonic generating loads and works as the harmonic compensation voltage source. The EMI input filter connected in series or parallel to the source.

The passive EMI filters improve the EMI noise attenuation without any complex control circuit. In [1]-[11] reported the closed loop controlled single stage PFC boost converter with EMI filter fed a resistive 
load. In this paper, the closed loop PI controlled single boost converter fed DC motor with input EMI filter has been introduced to reduce the harmonics.

\section{EMI SOURCES AND FILTERS}

The main sources of EMI generated in the power system due to power electronics converters and its associated loads i.e. nonlinear loads. The conducted emission caused by
a) Starting with $\mathrm{AC} / \mathrm{DC}$ motors
b) Fluorescent bulbs/ ballasts
c) Light dimmers
d) Microwave ovens
e) Microprocessors
f) Computers
g) Switched mode power supplies (SMPS)

\subsection{Need for EMI Input Filter}

The aim of the EMI filter was to reduce the interference caused either conducted or radiated from the power circuit. AC to DC or DC to AC power supply circuits or systems may generate more electrical noise that cannot be filtered out by its internal filter. The problems associated with EMI noise can be resolved by introducing an additional EMI filter on the source side of the power supplies
a) Suppress the emission at the source end.
b) Provide the inactive coupling path.
c) Ensure the receiver less vulnerable to the emission.

\subsection{EMI Filter Types}

EMI filters usually two types, passive and active filters. Passive $\mathrm{R}, \mathrm{L}$ and $\mathrm{C}$ electronic components which constitute the LC circuits. The unwanted EMI noise frequencies are greater than the normal signal frequencies. The EMI filter works by selectively blocking or shunting unwanted higher frequencies. The inductance of the EMI filter is used to allow the low frequency and block the high frequency. The capacitor in the EMI filter is used to bypass or shunt unwanted high-frequency noises. EMI filter takes an active part to attenuate the all undesirable noises in the power electronic device. The commonly used various filters are shown in Figure 2.1.a to d.

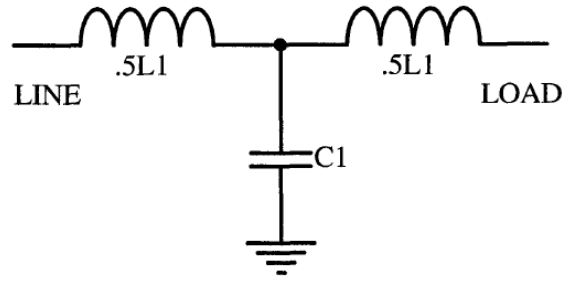

Figure 2.1.a. T Filter

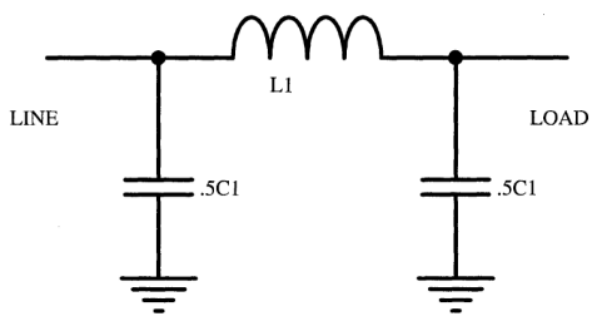

Figure 2.1.c. $\pi$ Filter



Figure 2.1.b. L Filter

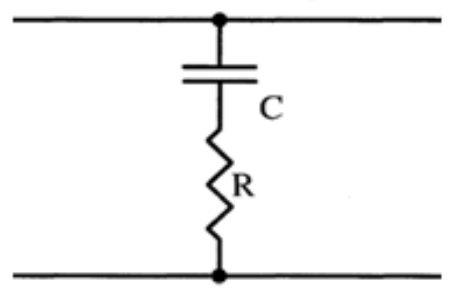

Figure 2.1.d. RC Filter

Common solutions to meet the EMC standards in power converters are using EMI filters. The filters are designed and validated with converter realization. The filtering techniques are invariably achieving the 
further EMI reductions necessary to satisfy EMC standards. It is desirable to implement cost-effective suppression methods in order to reduce the filtering characterization before designing and implementing the filter. Many filtering solutions based on passive and active network approaches have been introduced to attenuate conducted EMI. Presently the CM and DM filters are designed together with discriminating CM and DM noises for better performance [4-6].

Passive EMI filters are bulky in size and require multi-stage LC circuits to achieve significant highfrequency noise reduction. This results in higher cost and larger size of the power converter. A typical passive EMI filter designed for the suppression of Common Mode (CM) is shown in Figure 2.2.

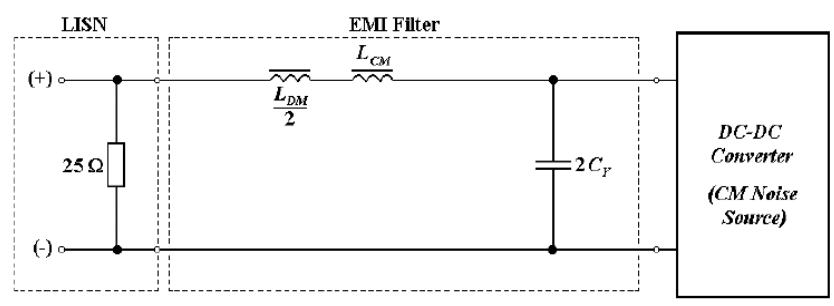

Figure 2.2. Equivalent circuit for $\mathrm{CM}$

\section{SINGLE BOOST CONVERTER CIRCUIT}

The conventional schematic diagram of a single boost converter circuit is shown in Figure 3.1. Boost converter where the output voltage is greater than the input voltage. The boost converter is also literally known as a step-up converter. A large inductor in series with the source voltage is essential. When the switch is on, the input current flows through the inductor and switch and the inductor stores the energy during this period. When the switch is off, the inductor current cannot zero instantaneously; this current is forced to flow through the diode and the load during this off period. As the current tends to decrease, the polarity of emf induced in $\mathrm{L}_{1}$ is reversed. As a result, the voltage across a load is the sum of supply voltage and inductor voltage and it is greater than the supply voltage. The main drawback of the single inductor boost converter is it could not avoid some natural power loss because of its structural arrangement with rectifier circuit on the source side.

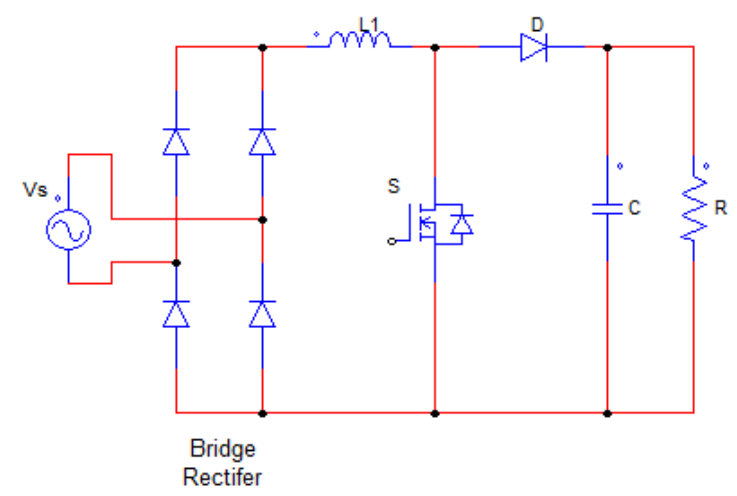

Figure 3.1. Single Boost converter Circuit

DC output voltage expression of the boost converter is given in (1) $V_{o}=\frac{V_{s}}{1-D}$, where, $\mathrm{D}-\mathrm{Duty}$ ratio or

cycle $=\mathrm{D}=\frac{T_{o n}}{T}, \mathrm{~T}=\mathrm{T}_{\text {on }}+\mathrm{T}_{\text {off }}$

$\mathrm{T}-$ Total time period 


\section{$\mathrm{V}_{\mathrm{s}}$ - Source voltage \\ $\mathrm{V}_{\mathrm{o}}$ - Output voltage \\ $\mathrm{T}_{\text {on }}$ - On time \\ $\mathrm{T}_{\text {off }}$ - Off time \\ $\mathrm{T}-$ Total time period}

The range of duty cycle is $0<\mathrm{D}<1$ and the output voltage is greater than the input voltage i.e. $\mathrm{V}_{\mathrm{o}}>\mathrm{V}_{\mathrm{s}}$. The overall block diagram of proposed system is shown in Figure 3.2.

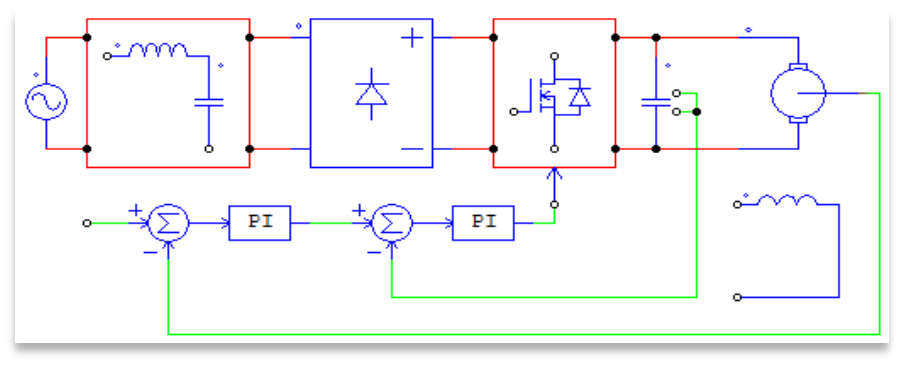

Figure 3.2. Overall Block diagram of Proposed system

\section{SIMULATION RESULT}

The simulation of single boost converter fed DC Motor without EMI filter was carried out using MATLAB/Simulink. Simulink model of single boost converter fed DC motor without input EMI filter is shown in Figure 4.1 and PI controlled DC motor with input EMI filter is shown in 4.2. The speed response of DC motor is shown in Figure 4.3 and the torque response of DC motor is shown in Figure 4.4. The spectrum analysis of THD in single boost converter fed DC motor without EMI filter is shown in Figure 4.5.

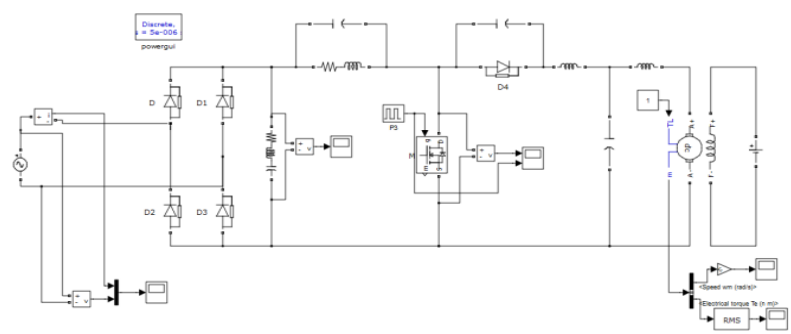

Figure 4.1. Simulink model of Single boost converter fed DC motor without EMI filter

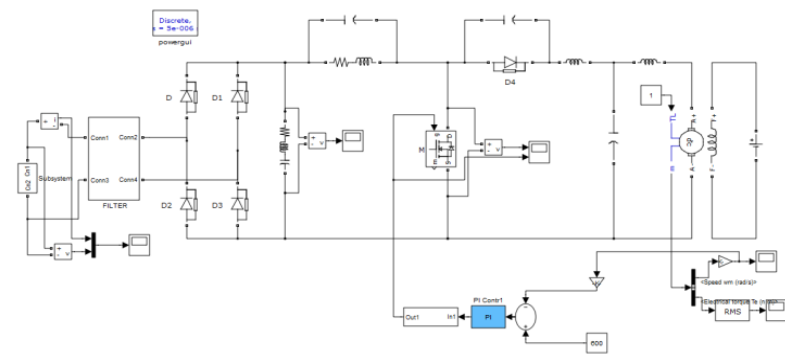

Figure 4.2. Simulink model of PI controlled Single boost converter fed DC motor with EMI filter 


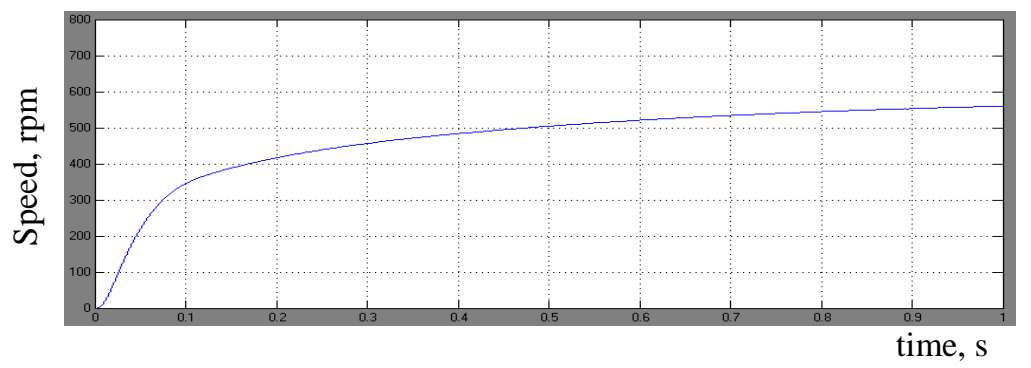

Figure 4.3. Speed response of DC motor without EMI filter

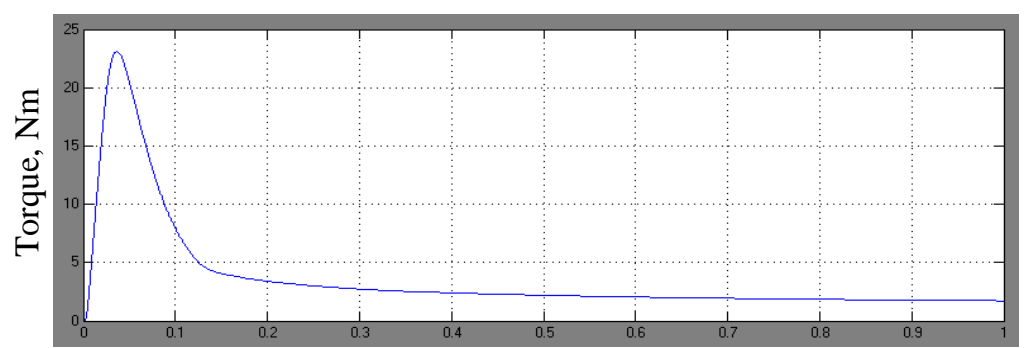

time, $s$

Figure 4.4. Torque response of DC motor without EMI filter

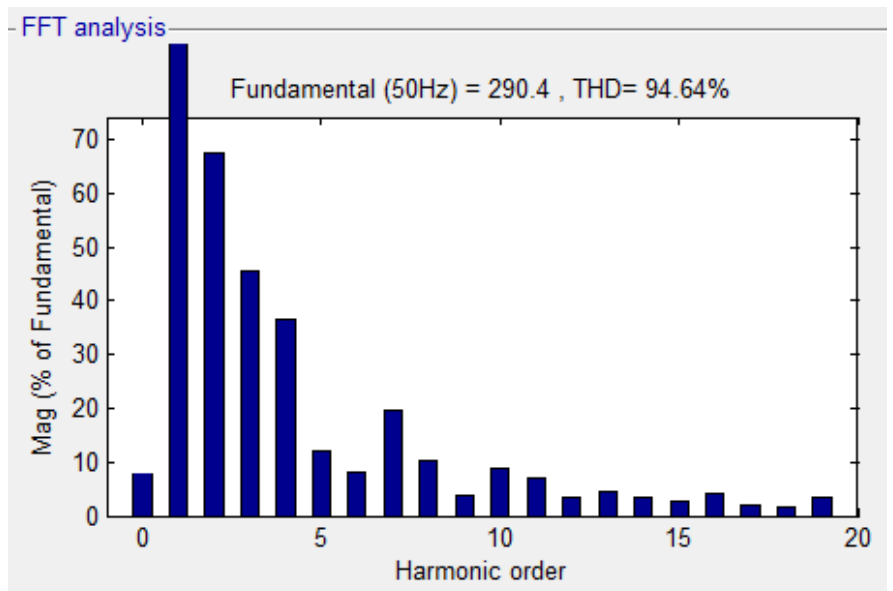

Figure 4.5. Frequency spectrum of THD in Single Boost converter fed DC motor without EMI filter

The speed response of a PI controlled DC motor with EMI filter is shown in Figure 4.6 and the PI controlled DC motor with EMI filter is shown in Figure 4.7. The spectrum analysis of THD in Single Boost converter fed DC motor with EMI filter is shown in Figure 4.8. It is interpreted that the speed and torque response of a PI controlled DC motor reaches a rated value in a smooth manner. The source current harmonic $\%$ THD has drastically decreased from $94.64 \%$ to $11.38 \%$. The comparative results of PI controlled DC motor with and without EMI input filter is given in Table 1. Simulation parameter is given in Table 2. 


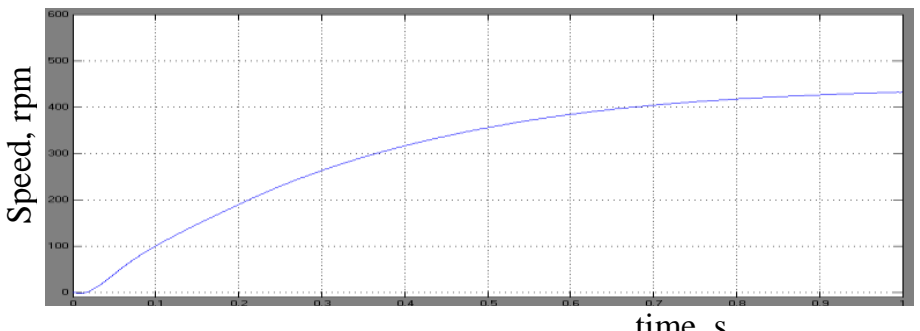

time, $s$

Figure 4.6. Speed response of a PI controlled DC motor with EMI filter

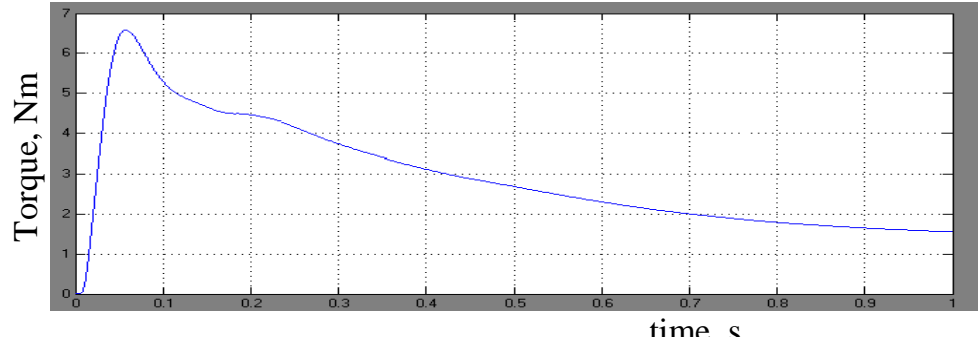

Figure 4.7. Torque response of a PI controlled DC motor with EMI filter

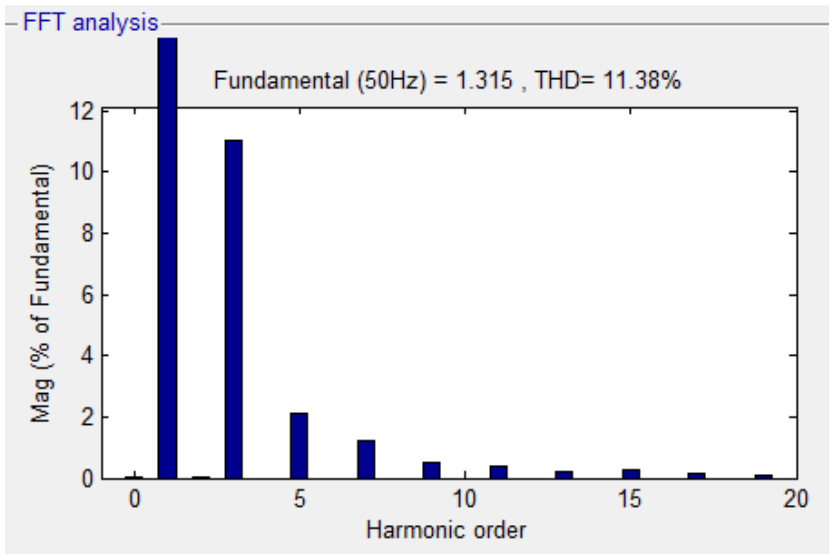

Figure 4.8. Frequency spectrum of THD in a PI controlled DC motor with EMI filter

Table 1 Comparison of THD Value With and Without EMI Filter

\begin{tabular}{cc}
\hline $\begin{array}{c}\text { PI Controlled Single Boost Converter fed } \\
\text { DC Motor }\end{array}$ & $\%$ THD \\
\hline without EMI Filter & $94.64 \%$ \\
with EMI Filter & $11.38 \%$ \\
\hline
\end{tabular}

Table 2 Simulation Parameters

\begin{tabular}{ll}
\hline \multicolumn{1}{c}{ Parameters } & \multicolumn{1}{c}{ Value } \\
\hline AC Supply & $100 \mathrm{~V}, 50 \mathrm{~Hz}$, Single Phase \\
DC Motor & $5 \mathrm{HP}, 1750 \mathrm{rpm}, 240 \mathrm{~V}$, Filed: $150 \mathrm{~V}$ \\
(Separately excited Shunt) & $\mathrm{K}_{\mathrm{p}}=1$ \\
PI Controller & $\mathrm{K}_{\mathrm{i}}=0.5$ \\
& $\mathrm{R}=0.01 \Omega \mathrm{L}=0.8 \mathrm{mH}$ \\
EMI Filter & $\mathrm{C}=1 \mu \mathrm{F}$ \\
\hline
\end{tabular}

\section{CONCLUSION}


The harmonic reduction using an EMI filter is discussed and demonstrated with help of PI controlled single boost converter supplied DC motor load. The simulation results of the single boost converter fed a DC motor load with and without EMI input filter are presented. The PI controller significantly reduces the source current harmonics in terms of \% THD

\section{REFERENCES}

[1] Mel Berman, "All about EMI Filters", http://electronicproduct.com, October 2008, pp: 51- 53.

[2] K.Manjula and S.Bhuvaneswari, "A Review of Analysis and Design of EMI Filters for Power Electronic Converters", International Research Journal of Engineering and Technology, vol.2, no.8, Nov.2015, pp.1640-1646.

[3] K. Mainali and R. Oruganti, "Conducted EMI Mitigation Techniques for Switch-Mode Power Converters: A Survey", IEEE Trans. Power Electron., vol. 25, no. 9, Sep. 2010, pp.2344-2356.

[4] S.P. Weber, E. Hoene, S. Guttowski, J. John, and H. Reichl, "Predicting parasitic and Inductive Coupling in EMI Filters", In Proc. IEEE 21st Annu. Appl. Power Electron. Conf. Expo., March 2006, vol. 1, pp. 1157-1160.

[5] M.L. Heldwein, "EMC filtering of three-phase PWM Converters", Ph.D. dissertation, Power Electron. Syst. Lab., Swiss Federal Inst. Technol., Zurich, Switzerland, 2007.

[6] H. Chung, S. Y. R. Hui, and K. K. Tse, "Reduction of Power Converter EMI Emission using Soft-Switching Technique", IEEE Trans. Electromagn. Compat., vol. 40, no. 3, pp. 282-287, Aug. 1998.

[7] Nidhal Y. Nasser, "Practical Approach in Designing Conducted EMI Filter to Mitigate Common Mode and Differential Mode Noises in SMPS", Journal of Engineering and Development, vol. 16, no.1, March 2012, pp.164-183.

[8] Ivana F. Kova cevi'c, Thomas Friedli, Andreas M.Muesing, "3-D Electromagnetic Modeling of EMI Input Filters", IEEE Transactions on Industrial Electronics, vol. 61, no. 1, January 2014, pp. 231-242.

[9] I. F. Kovacevic, T. Friedli, A. Muesing, and J. W.Kolar, "PEEC-based virtual design of EMI input filters," In Proc.IEEE Energy Convers. Congr. Expo., Sep. 2011, pp. 1935-1941.

[10] M.Gopinath, "EMI Analysis on Dual Boost Power Factor Correction Converter", IJERT, vol. 2, Issue 8, August 2013 pp.27582763.

[11] Rohit Chacha and Syed Naveed, "Closed loop Controlled PFC Boost converter with constant Output voltage and EMI Filter", IRJET, vol. 2, Issue 8, November 2015, pp.934-937.

\section{BIOGRAPHIES OF AUTHORS}

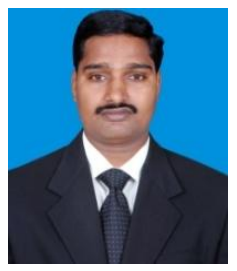

A. Sivakumar has obtained his BE degree (2001) in Electrical and Electronics Engineering from the University of Madras and ME degree (2005) in Power Electronics \& Drives from Anna University, Chennai. His current research area is a Harmonic Reduction and Speed control in induction motor drive systems. He has published four papers in international journals and two conference papers. He is an IEEE member and ACES. He is presently working as Associate Professor in the Dept. of EEE, Panimalar Engineering College, Chennai.

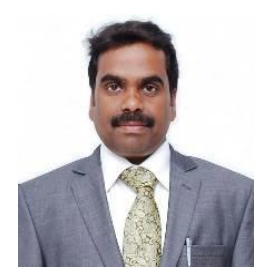

Dr.T.Muthamizhan received his BE degree in Electrical and Electronics Engineering from University of Madras in 1998, ME degree in Power Electronics \& Drives in 2005 and Ph.D in Electrical Drives in 2014 from the College of Engineering, Guindy, Anna University Chennai 600025. His area of interest includes Electric machines and drives, Power electronic converters, Renewable Energy Generation and Energy Storage, Smart Grid and Power Quality. He is the Member of IEEE, and Life member of ISTE, IEI and SESI. He is now working as Associate Professor in the Department of Electrical \& Electronics Engineering, Sri Sairam Institute of Technology, Chennai. 